\title{
Enhancing Learning in a Virtual Environment: Qualities of Learning in Different Learning Modes
}

\author{
Nicholas Mavengere, Mikko Ruohonen, Katriina Vartiainen \\ CIRCMI, Faculty of Natural Sciences, University of Tampere, Finland \\ \{nicholas.mavengere, mikko.j.ruohonen, katriina.vartiainen\}@uta.fi
}

\begin{abstract}
Virtual learning is increasingly common due to factors, such as technological advances and globalization. Research presented in this paper is based on a virtual ICT for Development -course that was offered three times by a Finnish university. The course participants were from Finland, Germany, South Africa and Kenya. During the three course implementations, three different learning modes traditional teacher-focused learning, team-work focused learning and a blend of the two - were utilized. Our research goal was to better understand practices that enhance the learning process in a virtual environment. We collected data by three online questionnaires that were sent to the course participants by email after completing the course. In total, we received 61 responses. We discovered that the students' perceptions of the richness in qualities of learning were different in each course. This paper discusses this difference in line with the different learning modes used. These results encourage us to further research the link between learning modes and qualities of learning to 1) validate the findings with a larger sample, 2) compare them to previous studies in the field, and 3) to potentially propose generalizability of the findings.
\end{abstract}

Keywords: virtual learning, virtual course, teacher-focused learning, team-work focused learning, qualities of learning

\section{Introduction}

Efforts to improve the learning process are ever required. This is due to the increasing possibilities of offering learning, for example, learning using social media and learning management systems. Especially, the technological advances of online and distance learning open up new avenues to the learning process and its research [1]. Thus virtual learning is well appreciated in theory and practice [2]. In addition, the learning process should always be improved in line with advances in learning technologies. But negative effects should also be unearthed and efforts to reduce their effects should be done. This is important in trying to maximize the gains from virtual learning and reduce the negative effects.

The background of this paper is in a virtual course that was offered at the University of Tampere in 2015-2016. The course was offered three times in total, during two academic years. We always tried to improve the learning process from the first experience which was traditional teacher-focused learning to the third experience which was team-work focused and the second experience which was the blend of the two, that is, the first and third course experience, and referred to as blended in this 
paper. This study is based on these experiences in an attempt to understand practices that enhance the learning process in a virtual environment. By enhancing the learning process we argue that qualities of learning should always be sought. Therefore, this study assesses the learning qualities in the three classes, namely, teacher-focused class no. 1, blended class no. 2 and team-work focused class no. 3 . The qualities of learning are elaborated in the next section. Thus, the research question is: How can the learning process be enhanced to promote the qualities of learning in a virtual environment?

The next section elaborates the qualities of learning, which are used as a measure in enhancing the learning process. After that, the virtual course conducted in three classes (class no. 1, 2 and 3 noted above) is described. Then, the data collection methods are described and results are highlighted, followed by discussion and conclusion.

\section{Qualities of Learning}

Vuopala, Hyvönen and Järvelä suggested seven qualities of learning derived and extended from [4]. They argued that the qualities are interrelated, interdependent interactive. These qualities of learning are as listed below:

1. 'Active - Learners' role in learning process is active; they are engaged in mindful processing of information and they are responsible for the result.

2. Constructive - Learners construct new knowledge on the basis of their previous knowledge.

3. Collaborative - Learners work together in building new knowledge in cooperation with each other and exploiting each other's skills.

4. Intentional - Learners try actively and willingly to achieve a cognitive objective.

5. Contextual - Learning tasks are situated in a meaningful real world tasks or they are introduced through case-based or problem-based real life examples.

6. Transfer - Learners are able to transfer learning from the situations and contexts, where learning has taken place and use their knowledge in other situations.

7. Reflective - Learners articulate what they have learned and reflect on the processes and decisions entailed by the process."

Additionally, we include the conversational quality of learning in our palette as an individual element, even though [3] viewed it as a part of the collaborative learning quality. The conversational quality is defined as "Learning is a social and dialogical process in which learners are able to utilize the knowledge of other members of the learning community during the knowledge building process"[3].

We used these qualities of learning as a measure to evaluate and improve the learning process. Thus, in this paper, they are understood as aspects that can enrich the learning process and experience of students. 


\section{The Virtual Learning Course}

The University of Tampere offered a virtual course, entitled Development 2.0, that is, Information and Communications Technologies for Development 2.0. The course was done with three groups of students, referred to as class 1 (Autumn semester 2015), class 2 (Spring semester 2016) and class 3 (Autumn semester 2016) [5].

In class 1, the 32 participants were from Finland, Germany, and South Africa. In the end, 31 of them completed the course. In class 2, there were 32 participants from Finland, Germany, and South Africa. 27 completed the course. Finally, class 3 had 57 participants who were from Finland, Kenya and South Africa. Of them, 17 completed the course. The Figure 1 shows the numbers of participants per class and teaching style.

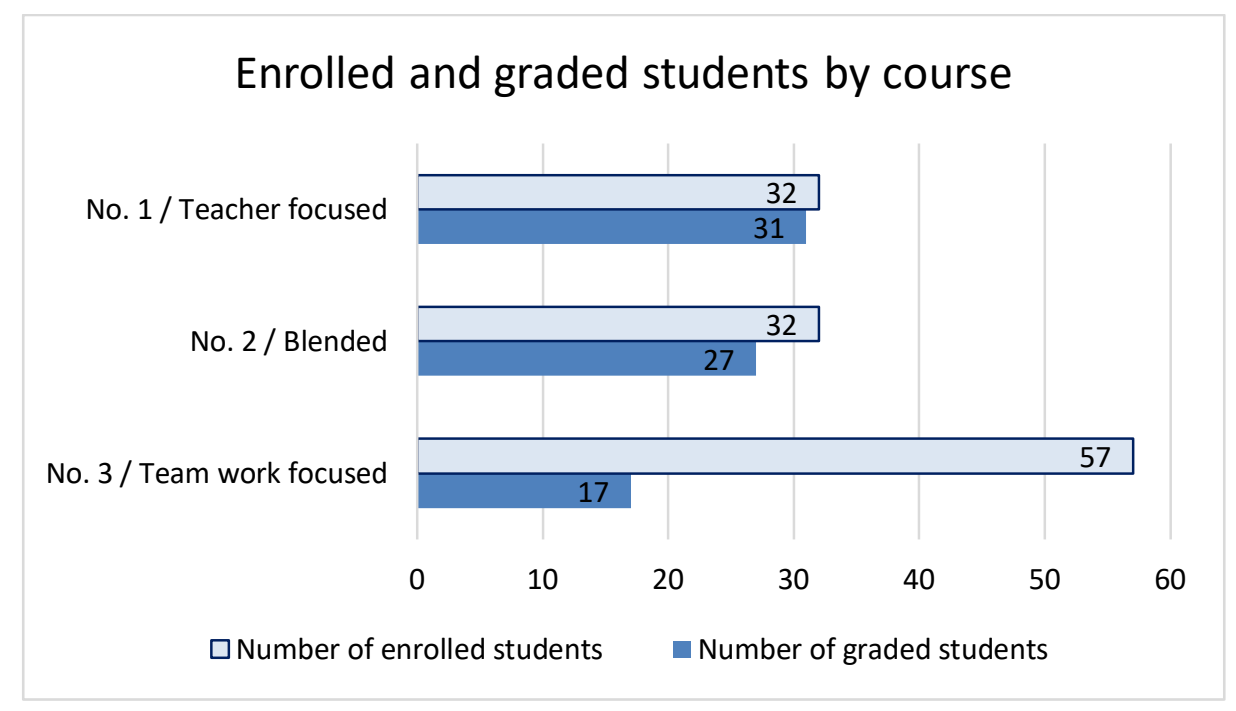

Fig. 1. Course participants

Three different but related teaching modes were used in the three classes namely teacher focused, blended and teamwork focused as shown in figure 1. In class one, teacher focused mode was such that the teacher uploads the learning material and the learners study and respond to the different tasks e.g. learning diaries and essays assessed by the teacher. Thus, the learning was mainly controlled and assessed by the teacher in class one. In class three, teamwork focused mode was such that the class tasks were mainly group work and the learners assessed each other's work [6]. For example, wiki construction tasks in which each group had a wiki page to develop and evaluate another group's page. Class two, referred to as blended, was the blend of class one and class three, that is, about half teamwork and also teacher focused tasks. 


\section{Data Collection Methods}

The data was collected in three online questionnaires that were sent to the course participants by email after completing the course. The questionnaires focused on the overall virtual learning experience of the students, while general comments regarding the course contents were also collected.

In this paper, we particularly focus on a multiple choice question which evaluated whether the virtual learning environment was experienced to provide a platform for the different qualities of learning that were described earlier in the paper.

The number of responses to the question under investigation per questionnaire are listed in Table 1. In conjunction with the questionnaire findings, the grades of the courses are analyzed in the next section, results.

Table 1. The number of included and excluded responses

\begin{tabular}{|l|l|l|}
\hline Questionnaire for & Number of included responses (n) & $\begin{array}{l}\text { Number of excluded } \\
\text { responses due to conflicting } \\
\text { answers }\end{array}$ \\
\hline Class 1 & 32 & 1 \\
\hline Class 2 & 16 & 1 \\
\hline Class 3 & 13 & 0 \\
\hline
\end{tabular}

\section{Results}

The three classes had different average, minimum and maximum grades as shown in Figure 2. There grades for the three classes are very close, no big difference noted. The teacher focused class 1 had the highest average grade (score 4,37) followed by team-work focused class $3(4,00)$, and finally the blended, class 2 , with the least average grade $(3,35)$. 


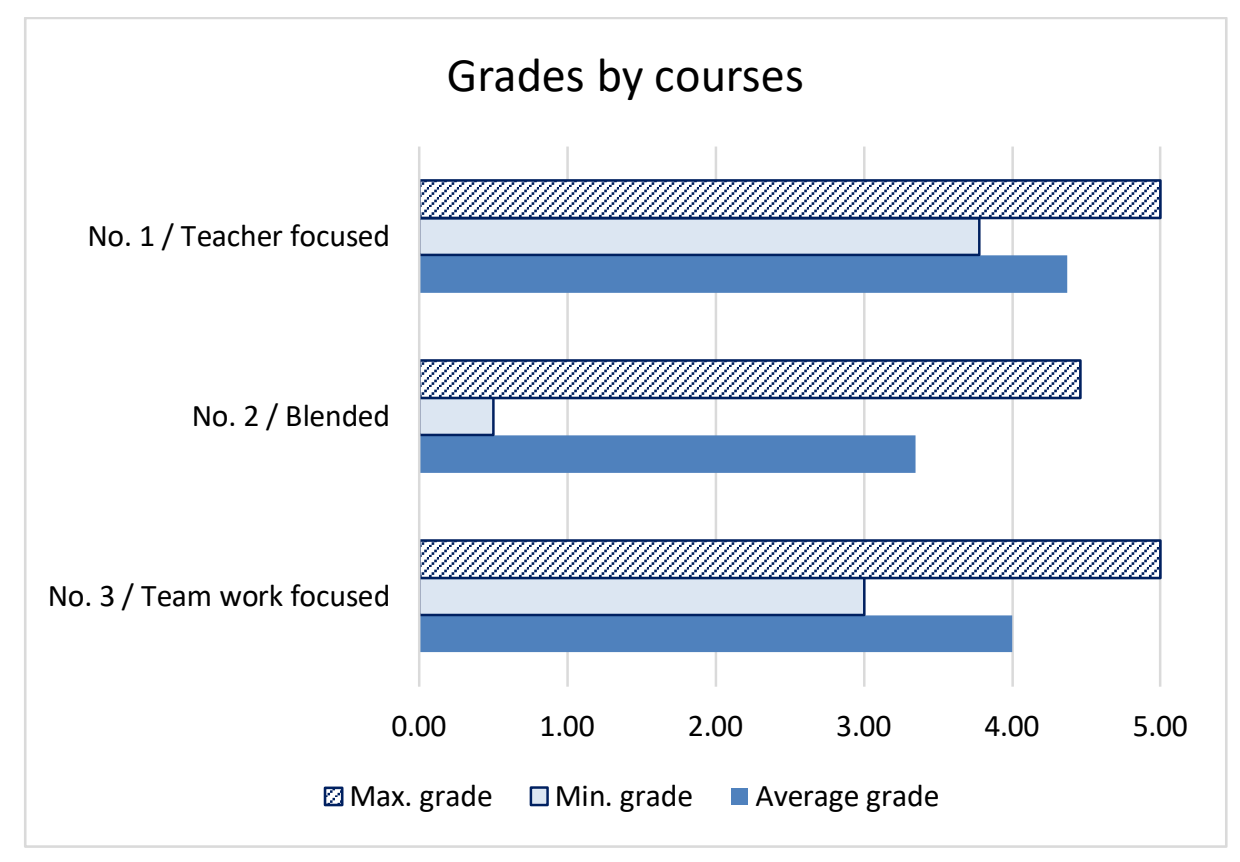

Fig. 2. Grades in the virtual course

When comparing the virtual learning experience between the classes from the perspective of whether the virtual learning environment provided a platform for the different qualities of learning, the results show that the respondents from the three classes perceived the qualities of learning somewhat differently. Figure 3 portrays these findings: Transfer and collaborative learning were the most perceived qualities of learning in the class 2, while for class 1 and 3 constructive learning was perceived the most.

It is interesting to note that almost all of the qualities of learning, that is, active, constructive, collaborative, conversational, and transfer learning, were perceived by $50 \%$ or more of the respondents for the classes 2 and 3. Only contextualized and reflective learning in class 2 , and intentional and contextualized learning in class 3 received a score lower than $50 \%$.

However, on the contrary, almost all the qualities of learning were perceived by fewer than $50 \%$ of respondents in class 1: Only constructive and contextualized learning received a score higher than $50 \%$. This could be an indication that team work focused learning is perceived as offering a richer set of qualities of learning than teacher focused. 


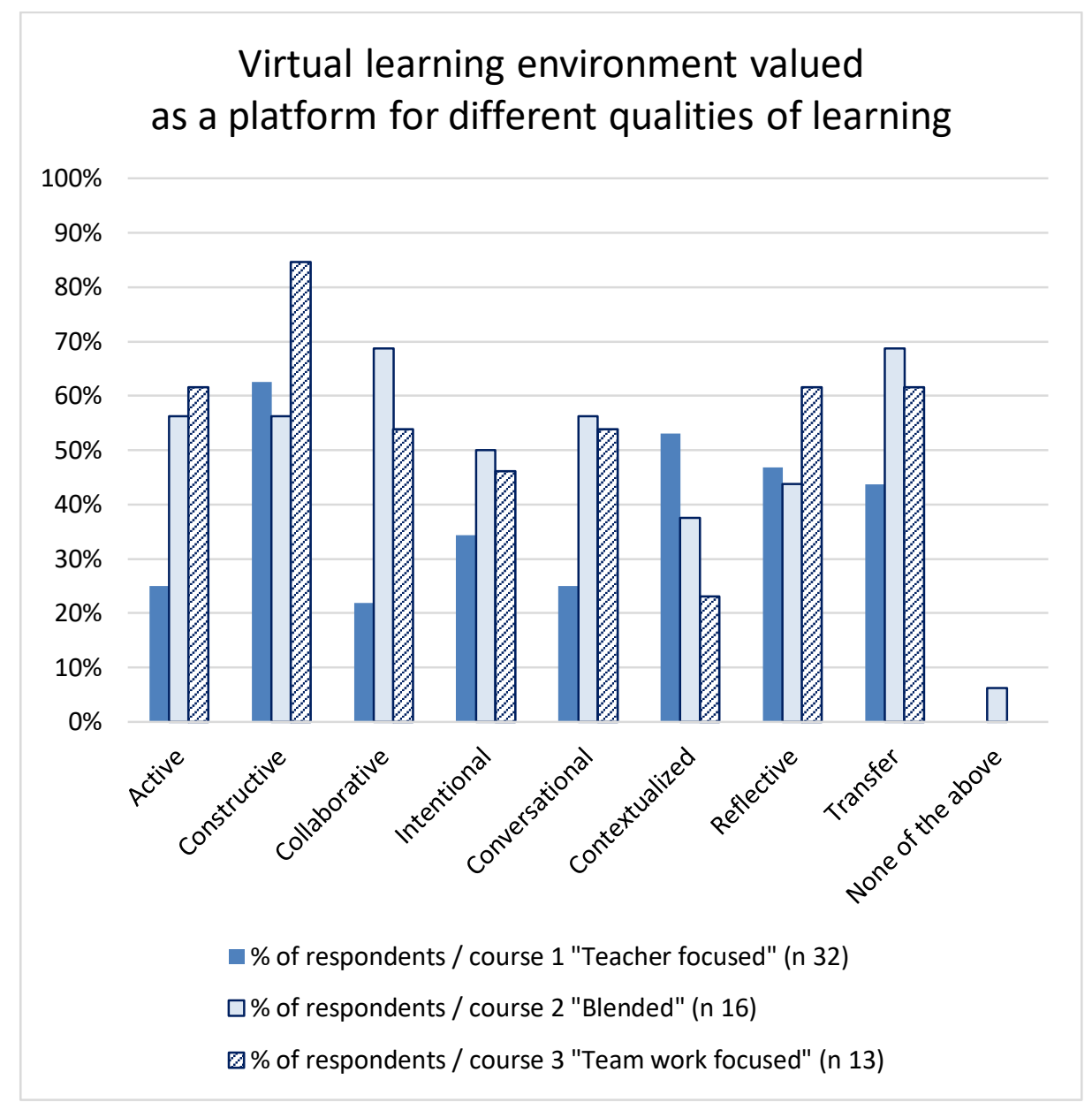

Fig. 3. Perceived qualities of learning in the three classes (class no. 1,2 and 3)

As we then investigated the relationship between the number of perceived qualities of learning and the average scores in the three classes, we found no straightforward positive relationship between a high average grade and a high number of perceived qualities. Please see Table 2 and Figure 4.

Table 2. The number of perceived qualities of learning and average grades

\begin{tabular}{|l|l|l|}
\hline Class & $\begin{array}{l}\text { Number of perceived qualities of } \\
\text { learning by } \mathbf{5 0 \%} \text { or more of the } \\
\text { respondents }\end{array}$ & Average grade \\
\hline Class 1 & 2 & 4,37 \\
\hline Class 2 & 6 & 3,35 \\
\hline Class 3 & 6 & 4,00 \\
\hline
\end{tabular}




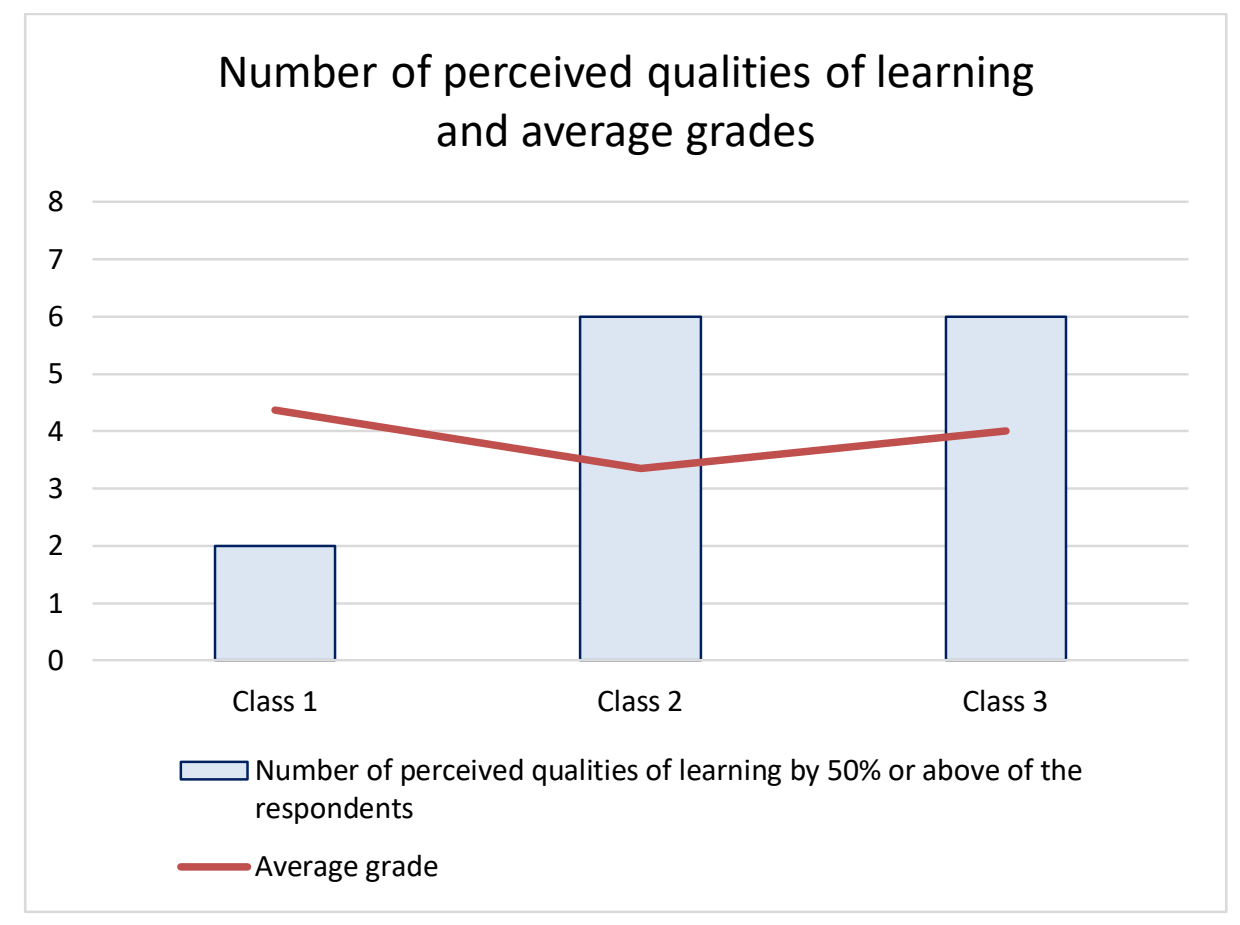

Fig. 4. The number of perceived qualities of learning and average grades

This observation is interesting. However, drawing conclusions from it would require further research on other, potentially influencing factors around the course implementations and perceived qualities of learning. These factors could include issues such as the timing of the course within the academic year, the previous online learning experience or the number of years of academic studies of the students.

\section{Discussion}

The increase in learning technologies due to the advances in technology also means an ever increasing room for improvement in terms of the learning process. This study looks at three learning processes, namely, teacher focused, team-work focused and a blend of the two referred to as blended. The results show varying learners' accomplishments from these three learning processes. For instance, the teacher focused had the highest students' completion ratio, that is, 31 out of the 32 students completed the course, and also the highest average grade. The team focused course seemed more demanding for the students with 17 out of 57 students completing the course. However, the team-work focused class had the highest number of different perceived qualities of learning [2]. It should be noted also that the courses were organized in different times of a year, this could have influenced the number of students, well as, the number of students who completed the course. For example, the course offered close to holiday season like Christmas tended to have few students. 
This could also influence the results as a whole, such as, perception towards the learning qualities and the class performance.

Mavengere and Ruohonen noted that the community of inquiry (COI) theoretical framework, Figure 5, emphasizes presence and interaction of cognitive, social and teaching elements. She further investigated the COI in a virtual learning environment and concluded that elements of cognitive, social and teaching presence were evident in online discussions. Thus, this is supporting our efforts of trying to improve interactions in virtual learning by introducing teams and group tasks. However, there are challenges in virtual learning, for instance, in a diverse class environment as in this research case, whereby students are from Finland, Kenya, Germany and South Africa. Our observation is that the noted advantages of team work in a virtual learning environment are more than the disadvantages.

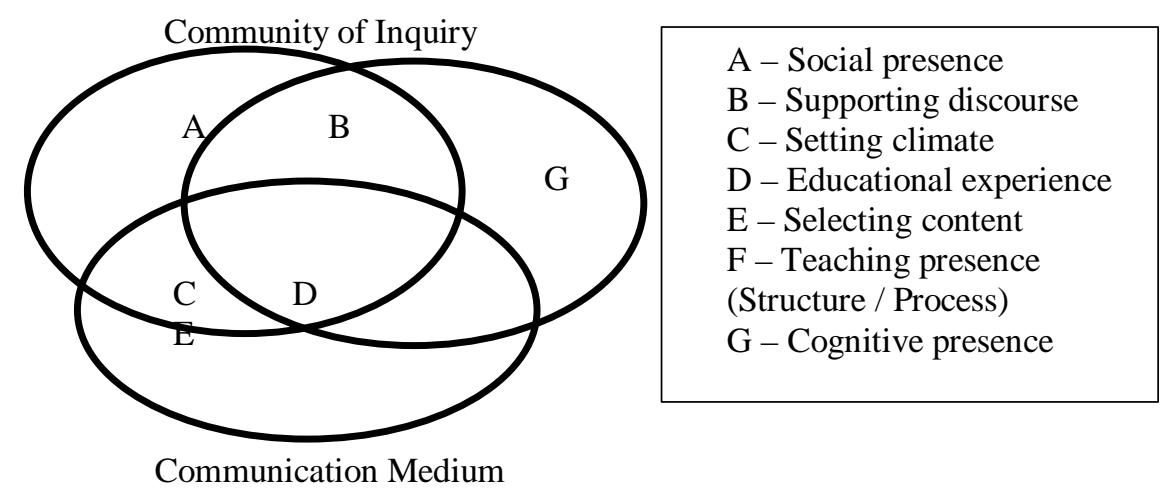

Fig. 5: Community of Inquiry Model [8]

Garrison, and Anderson noted that the term 'community of inquiry', Figure 5, was first used by [10] to refer to a learning environment where "students listen to one another with respect, build on one another's ideas, challenge one another to supply reasons for otherwise unsupported opinions, assist each other in drawing inferences from what has been said, and seek to identify one another's assumptions" [10]. The teacher facilitates such a learning environment. This supports the notion made in this research that a richer set of qualities of learning exists, when moving towards teamwork orientation

These results encourage us to further research the link between virtual learning modes and qualities of learning to validate the findings with a larger sample and interviews, compare results with other related studies in the field and gain further insights in improvements in the learning process.

\section{Conclusion}

Learning is integral in today's continuously changing environment. In addition, the global nature of the environment makes virtual learning attractive because of convenience, time and cost factors. This study highlights different learning processes in an attempt to promote virtual learning and maximize the benefits from the 
experience. Three learning processes, namely teacher focused, teamwork focused and a blend of the two in a virtual learning environment showed different results in terms of academic performance and learners' perception to the qualities of learning. Learning process should always be improved in line with the advances in learning technologies. But negative effects should also be unearthed and efforts to reduce their effects should be done.

\section{References}

1. Tobarra .L., Antonio Robles-Gómez, Salvador Ros, Roberto Hernández, Agustín C. Caminero, Analyzing the students' behavior and relevant topics in virtual learning communities. Computers in Human Behavior, 31: 659-669. http://dx.doi.org/10.1016/j.chb.2013.10.001 (2014)

2. Essi Vuopala, Pirkko Hyvönen, Sanna Järvelä, Interaction forms in successful collaborative learning in virtual learning environments. Active Learning in Higher Education, 17, 1 (2016), 25-38. Available at: http://journals.sagepub.com/doi/abs/10.1177/1469787415616730

3. Ruokamo H. and Pohjolainen S., "Pedagogical principles for evaluation of hypermediabased learning environments in mathematics,” J. Univers. Comput. Sci., vol. 4, no. 3, pp. 292-307, (1998).

4. Jonassen, D.H. Supporting communities of learners with technology: a vision for integrating technology with learning in schools. Educational Technology, 35(4), 60-63. (1995)

5. Mavengere N and Ruohonen M, "ICT4D 2.0 studies in virtual environment: Context and user needs to foster learning process,” in IST-Africa Week Conference, 2016, 1-8 (2016).

6. Kreijns K, Kirschner, P. A, Jochems, W and Van Buuren H, "Measuring perceived sociability of computer-supported collaborative learning environments," Comput. Educ., vol. 49, no. 2, pp. 176-192, (2007).

7. Lim H.L. (2007) Community of Inquiry in an Online Undergraduate Information Technology Course, Journal of Information Technology Education Volume 6, p. 154 -168

8. Garrison, D., Anderson, T., \& Archer, W. (2000). Critical inquiry in a text-based environment: Computer conferencing in higher education. Internet and Higher Education, 11(2), 1-14.

9. Garrison, D., \& Anderson, T. (2003). E-learning in the 21st century. London: RoutledgeFalmer.

10. Lipman, M. (1991). Thinking in education. New York: Cambridge University Press. 